\title{
A New Under-Frequency Load Shedding Scheme for Islanded Distribution Network
}

\author{
Hazlie Mokhlis, Member, IEEE \\ Mazaher Karimi, Student Member, IEEE \\ Amidaddin Shahriari, Student Member, IEEE \\ Dept. of Electrical Engineering \\ Faculty of Engineering, University of Malaya \\ Kuala Lumpur, Malaysia, 50603 \\ mazaherkarimi@yahoo.com
}

\begin{abstract}
High penetration of distributed generation (DG) in distribution level has open an opportunity for islanding operation of distribution networks. Through proper islanding operation, the reliability of the system can be improved by continuously supplying power from DG. However, an effective protection schemes for an islanded network are still an issue to be solved. Specifically to balance DG generation and load demand in order to maintain system frequency. Hence, an effective underfrequency load shedding scheme is required for an islanded distribution network which is not as strong as the grid. This paper presents a new under-frequency load shedding scheme for an islanded distribution network. A combination of adaptive under-frequency load shedding and state estimation is proposed for efficient and precise load shedding scheme. In this proposed method, overload is anticipated by utilizing an adaptive underfrequency load shedding scheme. Meanwhile, State estimation is used to estimate the load value. Finally, the estimated value of overload will be shed according to the estimated value of each bus demand.
\end{abstract}

Keywords-Under-Frequency Load Shedding; Distribution State Estimation; Distribution Network; Islanding Operation

\section{INTRODUCTION}

Islanding operation of Distributed Generations (DG) is a new approach to improve reliability of a distribution network. Through islanding, DG can supply electrical power to the distribution network during grid disconnection. Reliable DG and secure coordination with the grid system are necessary in order to design an islanding operation of distribution network. For this, IEEE 1547 group has produced a standard which serve as a guide for practicing an intentional islanding operation in an electric power system [1].

Although, the operation of DG can supply electrical power for distribution network, this operation can also bring up some concerns. Some of the main concerns of DGs in an islanded distribution network according to the IEEE Std. 1547.4-2011 are as follows:

- Equipment damage due to voltage and frequency variations.

- Sufficient and reliable DGs generation.

- System protection coordination.

- Voltage and frequency regulation.

- Load imbalanced or load and generation matching.

The most critical concern, in an islanding operation, is to regulate the voltage and frequency of the islanded system

\author{
Abd Halim Abu Bakar, Member, IEEE \\ Javed Ahmed Laghari \\ UM Power Energy Dedicated Advanced Centre \\ Level 4, Wisma R\&D UM, University of Malaya \\ Kuala Lumpur, Malaysia, 59990 \\ hazli@um.edu.my
}

within allowable range. Hence, specific considerations need to be taken when adequate generation of DGs do not exist to supply the loads in an islanded portion. Any change in generation and load immediately after system is islanded poses a challenge in controlling the voltage and frequency response. Normally, a large excess of load over local generation in the islanded system could result in a rapid frequency drop. The smaller system inertia tends to cause a quick frequency drop. It also has a limited reserve margins to cover for the shortfall of the generation. For such an imbalance power, DG would not be able to stabilize the frequency response. The only way to stabilize the frequency to its nominal value is to implement load shedding scheme.

The most common load shedding method applied by utilities is the conventional UFLS scheme. Although this method is simple and practical, it is known unreliable to shed right amount of load. [2-5]. Hence, an adaptive UFLS scheme was introduced to estimate the right amount of load need to be shed. The method used a simple expression of generator swing equation to estimate the imbalanced power in the electric power system. In the adaptive UFLS, power imbalanced is estimated based on the rate of change of frequency $(d f / d t)$ [6]. Different aspects of intelligent load shedding scheme have been also reported in the literature [7-10]. Intelligent scheme utilized power system automation, two-way high speed communication system, fast and accurate measurement units and other modern facilities to acquire knowledge and information regarding the network for intelligently and optimally shedding the load [11-14]. However, the effectiveness of this scheme depends on the availability of realtime monitoring in the network.

Although real-time measurement devices are very useful for system state monitoring and load shedding purposes, such devices are limited due to high cost of these devices. Only selected locations and critical points are being monitored in distribution network. Hence, the problem of limitation number of measurement equipment can be found in many conventional distribution networks. To address this problem, State Estimation (SE) can be used to approximate and estimate the system state at a bus where measurements are not available. Ever since the introduction of SE by F. C. Schweppe in the late of 1970 [15], various techniques are used to obtain a SE solution, which were well documented in [16-17]. Since the electric power grid becomes smarter, more distribution automation will be required and application of SE becomes 
more essential. An efficient method has been established to solve the distribution state estimation problems in an electric power system in [18]. A SE algorithm based on forwardbackward propagation with higher $R / X$ ratio of lines has been presented in [19]. A branch estimation based on SE method, suitable for real-time monitoring of distribution network is presented in [20].

This paper proposes a conceptual of a new load shedding scheme in an islanded distribution networks. The proposed strategy utilizes an adaptive UFLS scheme incorporating state estimation for distribution network application. The frequency of the center of inertia is used to measure the rate of change of frequency in order to estimate the power imbalance magnitude base on swing equation. At the same time, Distribution State Estimation (DSE) based on Weighted Least Square (WLS) method to find and capture a network operation point is utilized. A composite load model is performed in state estimation to compute an accurate value of active and reactive power of various types of loads such as industrial, commercial and domestic. It would be able to shed the load in accordance to the load priority. The proposed scheme is implemented to an intentional islanding operation considering Malaysia's existing distribution network that consists of two small units of hydro generation connected in parallel to the grid.

\section{PROPOSED UFLS SCHEME}

The proposed method combined an Adaptive UnderFrequency Load Shedding (AUFLS) and DSE for islanding operation of distribution network. As reported in the literature, AUFLS technique executes the load curtailment by measuring the Rate of Change of Frequency (ROCOF) in the system immediately after the occurrence of the disturbance, at $t=0^{+} \mathrm{s}$. Then, it computes the power imbalance (that causes the frequency drop) in the system based on simple expression of the generator swing equation. The scheme tries to shed right amount of load which is close to the estimated power imbalance. However, an unanswered question remains as to what are the best buses to distribute the calculated deficit.

Therefore, the proposed method utilizes DSE to estimate the online value of power for load at each bus. DSE program perform as a real-time monitoring device in the distribution network. In addition, the load shedding is performed according to the load priority in the network. The loads are classified into 3 categories; vital, semi-vital and non-vital. Fig. 1 illustrates the overall concept of load shedding scheme for an islanded distribution network connected with Mini Hydro power plants.

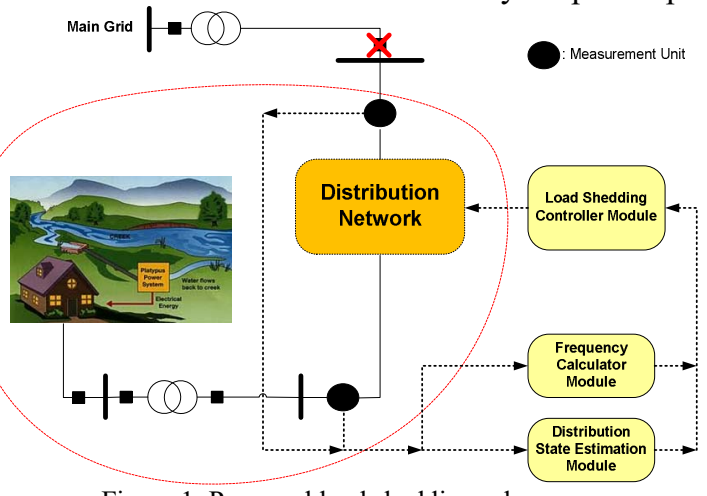

Figure 1. Proposed load shedding scheme
The scheme consists of three main modules; (a) Frequency Calculator Module (FCM), (b) Load Shedding Controller Module (LSCM) and (c) Distribution State Estimation Module (DSEM).

\section{A. Frequency Calculator Module}

The FCM will continuously calculate the frequency of the distribution network. It monitors the voltage of the network and then calculates the system frequency based on the zero crossing technique. During system disturbances, the generators are disturbed by inter generator oscillations and their deceleration or acceleration rates are not the same. Therefore, for the power imbalance calculation, the frequency of the Center of Inertia (COI) is considered [21-22]. This frequency is then compared to the frequency protection setting of each generator. If the frequency lies outside the range (less than $47.5 \mathrm{~Hz}$ or greater than $52.5 \mathrm{~Hz}$ ), both generators will be tripped off by an under or over frequency relay, which in practice is available to protect the generator.

\section{B. Distribution State Estimation Module}

The global measurement vector is pointed out by $\boldsymbol{Z}$, in a power system comprising distribution and transmission system. For an $N$-bus power system with $m$ measurements, assume $\boldsymbol{r}$ is an error vector with standard Gaussian that has a zero mean and variance $\sigma^{2}$. The measurement equation can generally be expressed as a function in (1):

$$
Z_{i}=h_{i}(x)+r_{i}, \quad i=1,2, \ldots, m
$$

Where

- $\quad Z_{i}$ is the vector of measurements

- $x$ is the state vector

- $\quad h_{i}(x)$ is the measurement matrix of the nonlinear function

- $\quad r_{i}$ is the measurement errors vector.

The classical WLS method will achieve the estimate value of $x$, which minimizes the objective function as describe in (2):

$$
J(x)=\sum_{i=1}^{m} \frac{\left(Z_{i}-h_{i}(x)\right)^{2}}{R_{i}}
$$

- $R_{i}$ diagonal matrix of $\left[1 / \sigma_{1}{ }^{2}, 1 / \sigma_{2}{ }^{2}, \ldots, 1 / \sigma_{m}{ }^{2}\right]$

- $\quad \sigma_{m}{ }^{2}$ is the variance of the $m$ th measurement error.

The best state estimate can be obtained by solution of the following equation. It is computed to reflect the expected accuracy of the corresponding meter used.

$$
[G(x)]\left[\Delta x^{k+1}\right]=\left[H\left(x^{k}\right)\right]^{T}[R]^{-1}\left[Z-h\left(x^{k}\right)\right]
$$

Where

- $\quad H(\mathrm{x})$ is the Jacobian matrix of the measurement function

- $G(\mathrm{x})$ is called the Gain matrix; it can be defined and formulated in (4) as follow:

$$
[G(x)]=\left[H\left(x^{k}\right)\right]^{T}[R]^{-1}\left[H\left(x^{k}\right)\right]
$$

System state will be solved iteratively, by (4) to minimize such errors and find an optimal estimate. In addition, the measurement matrix can be of a variety of most commonly used measurements in the practical system. The proposed DSEM is used real-time measurements as line power flows, pseudo measurements as a bus power injections and bus voltage magnitudes in order to construct the measurement matrix. Pseudo measurements are needed to assist convergence 
of the state estimator for distribution network, since real-time information is very limited in a conventional distribution system. Otherwise, the convergence of state estimator cannot be attained. Composite load model is chosen in order to represent a mix type of load in DSEM [23]. The load values will also be updated within iterations in respect to the system voltage.

\section{Load Shedding Controller Module}

In the LSCM, the amount of loads that are needed to be shed is determined and calculated. A certain delay time equal to $100 \mathrm{~ms}$ which comprises communication, calculation and circuit breaker opening time is being considered in this module. The LSCM will have to decide the power imbalanced value based on the ROCOF.

This strategy is to address the changes of frequency due to sudden increment of load in an islanded system. In this strategy, the amount of load to be shed depends on the disturbance magnitude. It is estimated based on the amount of power imbalance following frequency deviation in the system. The amount of power imbalance is estimated by using the $i$ th generators swing equation which is expressed in (5):

$$
\Delta P=\frac{2 \times \sum_{i=1}^{N} H_{i}}{f_{n}} \times \frac{d f_{c}}{d t}
$$

Where

- $\quad H$ is the generator inertia constant in seconds

- $\quad f c$ is the frequency, Hertz

- $\quad f n$ is the rated value of frequency, Hertz

- $\quad N$ is the number of generators

$\Delta P$ is the imbalance power, per-unit.

In (5), the magnitude of ROCOF $\left(d f_{c} / d t\right)$ is utilized to estimate the power imbalance. If ROCOF is less than zero and the system frequency fall less than $49.5 \mathrm{~Hz}$ then the decision is made to shed some of the loads. In this case, the LSCM will estimate the amount of load needed to be shed by using the swing equation. However, the magnitude of ROCOF is valid immediately after the occurrence of the disturbance due to the dynamic response of the control elements such as turbine, governor, load and generator. Consequently, the unknown value of $\Delta P$ is estimated by solving (5).

\section{VALIDATION OF THE PROPOSED LOAD SHEDDING}

The test system consists of 34 buses, 27 lumped loads with 2 mini hydro generators was modeled using PSCAD/EMTDC software. The mini hydro generators rated at 2MVA with $2.5 \mathrm{~s}$ of constant inertia are operated at $3.3 \mathrm{kV}$. Two parallel units of 2MVA generator transformer were connected to the DGs to step up the voltage level to $11 \mathrm{kV}$. Each load is connected with motorized switchgear that can be remotely controlled for load shedding purposes. Non-Elastic Water Column without Surge Tank and PID Controls including Pilot and Servo Dynamics model are used as a hydro turbine and governor model, respectively. IEEE Alternator Supplied Rectifier Excitation System is also chosen as an excitation model. The model parameters are shown in Table I, II and III, respectively.
TABLE I. HYdraUliC TURBINE PARAMETERS

\begin{tabular}{cccc}
\hline \hline Parameter & Value & Parameter & Value \\
\hline $\boldsymbol{T} \boldsymbol{W}$ & 1.2 & Initial output power & 0.7 \\
$\boldsymbol{f} \boldsymbol{P}$ & 0.02 & Initial operating head & 1.0 \\
$\boldsymbol{D}$ & 0.5 & Rated output power & 1.0 \\
\hline \hline
\end{tabular}

TABLE II. GOVERNOR PARAMETERS

\begin{tabular}{cccc}
\hline \hline Parameter & Value & Parameter & Value \\
\hline $\boldsymbol{K P}$ & 2.25 & $\boldsymbol{T C}$ & 0.2 \\
$\boldsymbol{K I}$ & 0.37 & $\boldsymbol{T D}$ & 0.2 \\
$\boldsymbol{K} \boldsymbol{D}$ & 0.9 & Max gate opening & 0.16 \\
$\boldsymbol{T} \boldsymbol{A}$ & 0.05 & Max gate closing & 0.16 \\
$\boldsymbol{R} \boldsymbol{P}$ & 0.04 & Dead band value & 0 \\
Max gate position & 1.0 & Min gate position & 0 \\
\hline \hline
\end{tabular}

TABLE III. EXCITATION PARAMETERS

\begin{tabular}{|c|c|c|c|}
\hline Parameter & Value & Parameter & Value \\
\hline$T C$ & 0 & $K F$ & 0.03 \\
\hline$T B$ & 0 & $T F$ & 1 \\
\hline $\boldsymbol{K} \boldsymbol{A}$ & 400 & $T E$ & 0.8 \\
\hline $\boldsymbol{T A}$ & 0.02 & $K E$ & 1 \\
\hline$V A M A X$ & 14.5 & $K C$ & 0.2 \\
\hline$V A M I N$ & -14.5 & $K D$ & 0.38 \\
\hline$V R M A X$ & 6.03 & VRMIN & -5.43 \\
\hline$S E(V E 1)$ & 0.1 & $S E(V E 2)$ & 0.03 \\
\hline VE1 & 4.18 & VE2 & 3.14 \\
\hline
\end{tabular}

\section{Simulation Results}

The system state variable (i.e. active power, reactive power and voltage) are monitored by the DSEM. The system frequency is also calculated by FCM to prepare the system information for LSCM. The LSCM collect the data from FCM and DSEM to determine or estimate the amount of power imbalance and accordance load need to be shed based on DSE values.

In order to test the proposed scheme, an intentional islanding is performed to the test system. In this case, the distribution network is disconnected from grid to operate in an islanding mode. Two scenarios are considered, base and peak load. The total load demand for base and peak load is $2.42 \mathrm{MW}$ and 3.16MW respectively.

Various events are simulated to study the effectiveness of the proposed load shedding scheme. The events such as trip the generator number 2 and sudden connection of load are selected as the disturbance. These events are applied in the test system at time $t=5$ seconds. The scheme should be able to cope with the different range of power imbalances between load and generation following the events. Trip the generator number 2 is considered in case I and the sudden connection of load is simulated in case II.

\section{A. Case I: Trip of the Generator 2}

In this case, loss of the generator number 2 is simulated. Frequency responses for base and peak load scenarios are shown in Fig. 3. Since the loads in the islanded system are supplied with two small hydro DGs, loss of one DG will give a great impact to the island. As a result of losing half of the island generation (1.58MW in peak load case), the system frequency has dropped, tremendously. Aberration of the $d f / d t$ versus system frequency is illustrated in Fig. 4. 


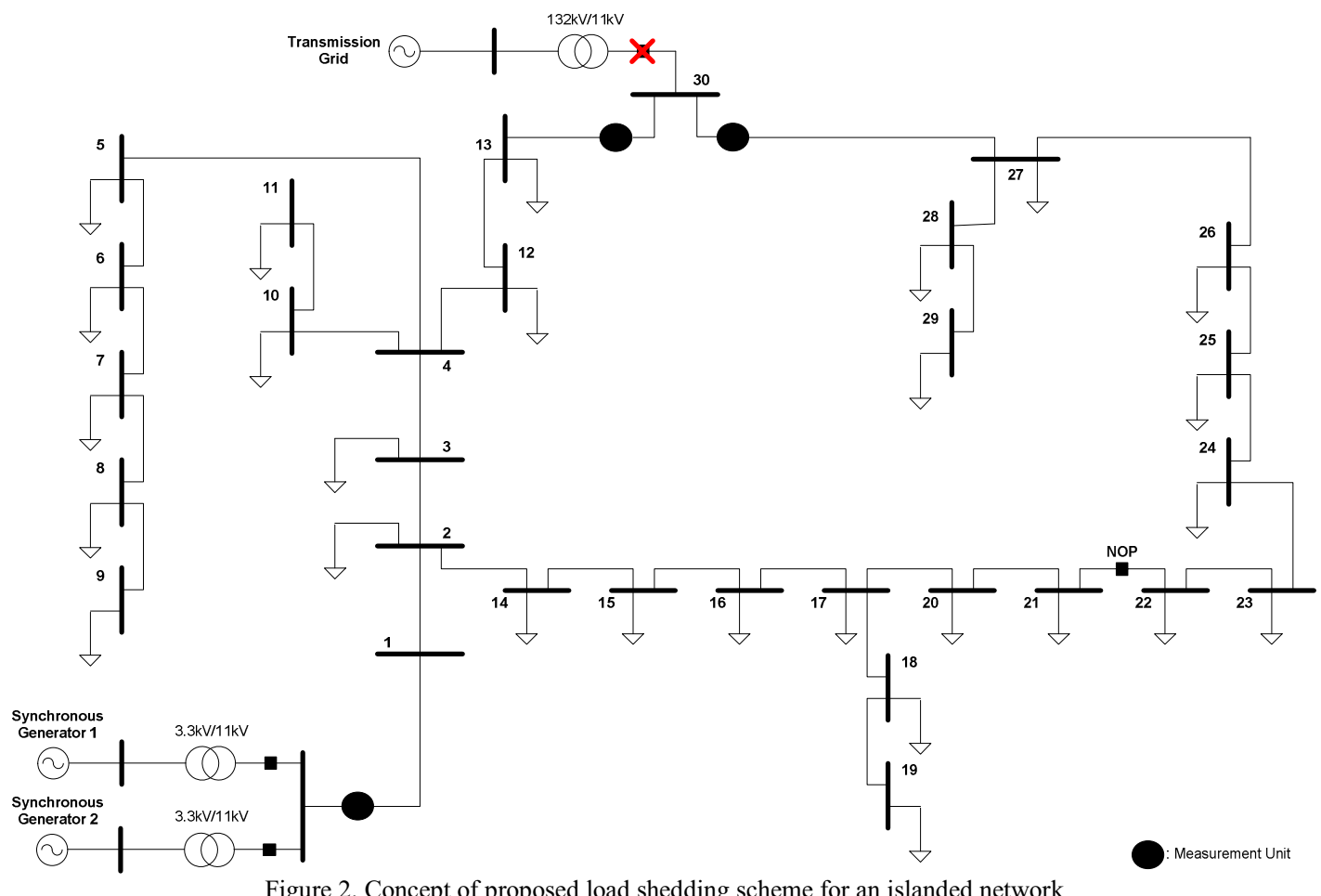

Figure 2. Concept of proposed load shedding scheme for an islanded network

TABLE IV. AMOUNT OF LOAD SHEDDING BY LSCM IN CASE I

\begin{tabular}{lcc}
\hline \hline Load Case & Power Imbalance (MW) & Load Shed (MW) \\
\hline Base Load & 1.21 & 1.009 \\
Peak Load & 1.58 & 1.468 \\
\hline \hline
\end{tabular}

In response to the event and to stabilize the islanded system, the LSCM would immediately trip significant numbers of load feeders. Optimum load shedding value for proposed method is presented in Table IV. The total loads shedding for both scenarios are observed. As shown in Fig. 3, system frequency for base and peak load drop to $48.156 \mathrm{~Hz}$ and 47.958 $\mathrm{Hz}$, respectively; then slowly restores to its nominal value.

\section{B. Case II: Sudden Connection of a Load}

In this case, the sudden connection of load in the islanded system for base and peak load is simulated. To create the overload disturbances, various loads are connected to the bus number 12 at simulation time, $t=5 \mathrm{~s}$. These rated values are $0.30 \mathrm{MW}$ and $0.45 \mathrm{MW}$. System frequency responses for base load demand are illustrated in Fig. 6. Following 0.3MW and $0.45 \mathrm{MW}$ overload disturbances the frequency is dropped to 49.327 Hz and $49.092 \mathrm{~Hz}$, respectively. The LSCM is compute the amount of load need to be shed based on estimated value of AUFLS. These values are presented in Table V. The total powers of load shedding for both scenarios are observed in this table. The difference value is supplied by spinning reserve of the generators and other frequency controller devices. Fig. 7 is demonstrated the frequency response versus the $d f / d t$ of the network. It is observed that the system frequency could be converged and restored back to the normal value after applying the load shedding.
For peak load case, the LSCM is also compute the amount of load need to be shed based on AUFLS and DSE. Fig. 8 shows the frequency response of the system in this case. The amount values of load shedding are presented in Table VI. Fig. 9 is illustrated the $d f / d t$ versus the frequency response of the network. It is observed that the system frequency could be converged and restored back to the normal value after applying the load shedding.

TABLE V. AMOUNT OF LOAD SHEDDING FOR BASE LOAD IN CASE II

\begin{tabular}{ccc}
\hline \hline Load Case & Power Imbalance (MW) & Load Shed (MW) \\
\hline Base Load & 0.30 & 0.227 \\
Base Load & 0.45 & 0.290 \\
\hline \hline
\end{tabular}

TABLE VI. Amount of LOAD SHEDding For PEAK LOAD IN CASE II

\begin{tabular}{ccc}
\hline \hline Load Case & Power Imbalance (MW) & Load Shed (MW) \\
\hline Peak Load & 0.30 & 0.113 \\
Peak Load & 0.45 & 0.284 \\
\hline \hline
\end{tabular}

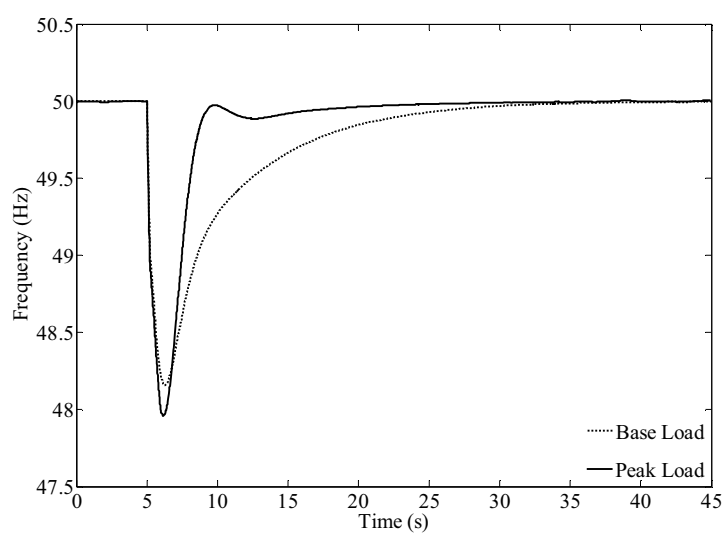

Figure 3. Frequency response of the network for case I 


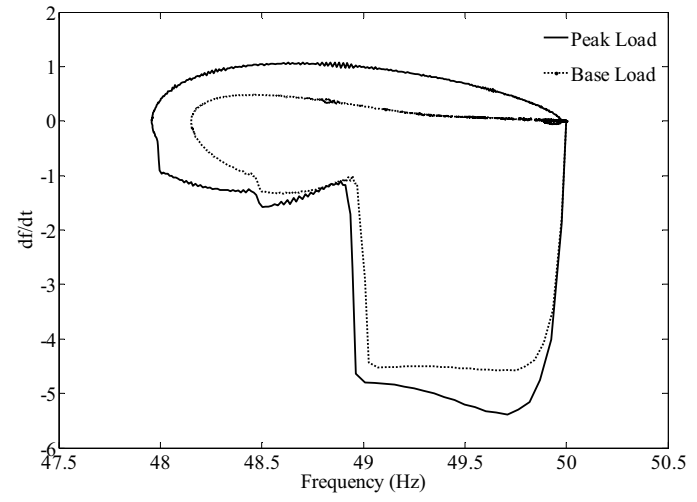

Figure 4. $d f / d t$ versus frequency response in case I

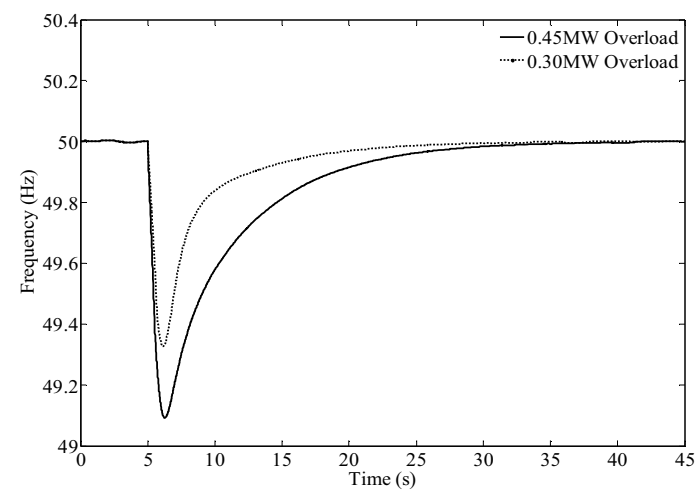

Figure 6. Frequency response of the overload for case II

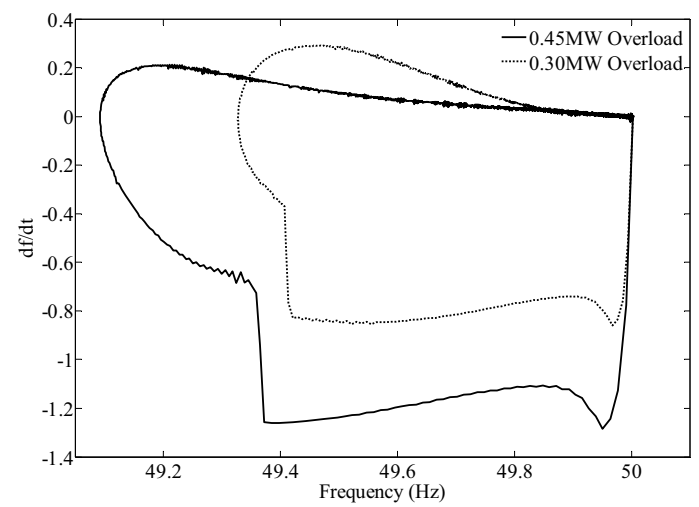

Figure 7. Frequency response versus $d f / d t$ in case I

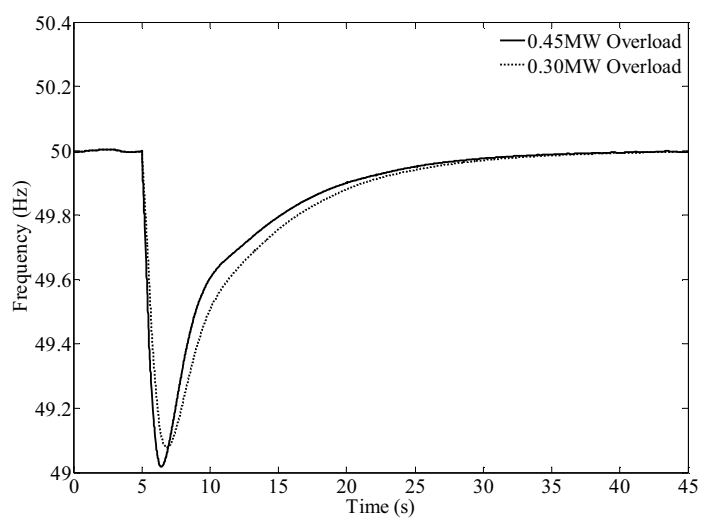

Figure 8. Frequency response of peak load for case II

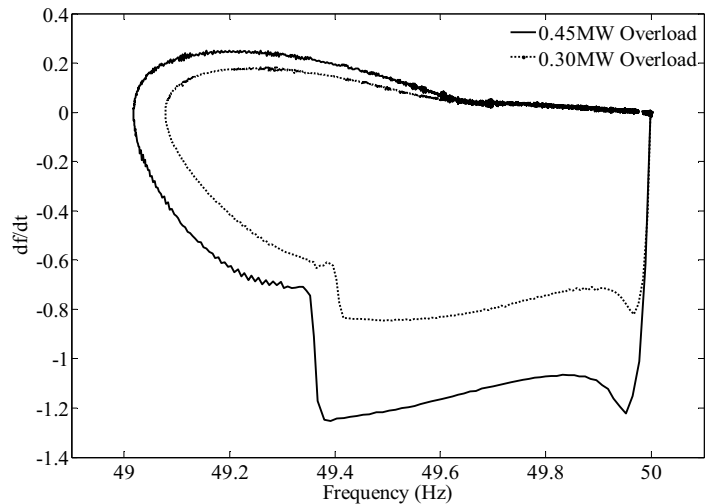

Figure 9. $d f / d t$ versus frequency response of peak load in case II

\section{CONCLUSION}

This paper proposed a new load shedding scheme based on an Adaptive Under-Frequency Load Shedding and Distribution State Estimation. An adaptive under frequency load shedding is applied to improve the estimation of disturbance magnitude in the system. Meanwhile, State estimation is used to estimate the load values at each bus in the system. By combining the mentioned methods, the proposed scheme is accurate and suitable for conventional distribution networks.

The effectiveness and robustness of the proposed scheme has been tested and results show the ability of load shedding in an islanded distribution network for preserving load generation balance. It is observed that the proposed scheme manages to immediately perform the load shedding in distribution network. The required amounts of load can be shed according to the well estimation of power imbalance. Of significance is that the scheme has proved to be an essential tool for a successful islanding operation.

\section{ACKNOWLEDGMENT}

This work was supported by the HIR/MOHE research Grant (Grant code: D000004-16001) and postgraduate research fund (PPP) Grant (Grant code: PS009-2012A).

\section{REFERENCES}

[1] "IEEE Guide for Design, Operation, and Integration of Distributed Resource Island Systems with Electric Power Systems," IEEE Std. 1547.4-2011, 2011.

[2] Hasmaini Mohamad, Hazlie Mokhlis, Ab Halim Abu Bakar, Hew Wooi Ping, " A review on islanding operation and control for distribution network connected with small hydro power plant," Renewable and Sustainable Energy Reviews, Vol. 15, pp. 3952-3962, 2011.

[3] V.V. Terzija, H.J. Koglin, "Adaptive underfrequency load shedding integrated with a frequency estimation numerical algorithm," IEE Proc Gener. Transm. Distrib., Vol. 149, N. 6, pp. 713-718, 2002.

[4] "IEEE Recommended Practice for Utility Interface of Photovoltaic (PV) Systems," IEEE Std. 929-2000, p. i, 2000.

[5] "IEEE Standard for Interconnecting Distributed Resources With Electric Power Systems," IEEE Std 1547-2003, pp. 1-16, 2003.

[6] V. V. Terzija and H. J. Koglin, "Adaptive underfrequency load shedding integrated with a frequency estimation numerical algorithm," IEE Proceedings Generation, Transmission and Distribution, vol. 149, pp. 713-718, 2002.

[7] X. Ding and A. A. Girgis, "Optimal load shedding strategy in power systems with distributed generation," in IEEE Power Engineering Society Winter Meeting, pp. 788-793 vol.2, 2001. 
[8] V. Terzija, "Adaptive underfrequency load shedding based on the magnitude of the disturbance estimation," IEEE Transactions on Power Systems, vol. 21, pp. 1260-1266, 2006.

[9] Rasha M. EL Azab, E. H. Shehab Eldin, P. Lataire, M. M. Sallam, "Power Measurement for the AUFL," International Review on Modelling and Simulations, vol. 4. N. 5, pp. 2285-2290, 2011.

[10] S. Ramesh, A. Krishnan, "Fuzzy Logic Based Frequency Stabilization in a Parallel AC-DC Multi Area Non Reheat Thermal Power Systems," International Review on Modelling and Simulations, Vol. 3. N. 4, pp. 590-597, 2010.

[11] F. Shokooh, et al., "Intelligent Load Shedding," IEEE Industry Applications Magazine, vol. 17, pp. 44-53, 2011.

[12] J. Jung, et al., "Adaptation in load shedding under vulnerable operating conditions," IEEE Transactions on Power Systems, vol. 17, pp. 1199$1205,2002$.

[13] F. Shokooh, et al., "An intelligent load shedding (ILS) system application in a large industrial facility," Industry Applications Conference, Fourtieth IAS Annual Meeting. Conference Record of the 2005, pp. 417-425 Vol. 1, 2005.

[14] D. Andersson, et al., "Intelligent load shedding to counteract power system instability," Transmission and Distribution Conference and Exposition: Latin America, 2004 IEEE/PES, pp. 570-574, 2004.

[15] F. C. Schweppe, J. Wildes, and D. B. Rom, "power system static state estimation-Part I, II, III," IEEE Trans. Power App. Syst., vol. PAS-89, no. 1, pp. 120-135, Jan. 1970.
[16] Y. F. Huang, et al., " State Estimation in Electric Power Grid: Meeting New Challenges Presented by the Requirements of the Future Grid," IEEE Signal Processing Magazine, vol. 29, N. 5, pp. 33-43, 2012.

[17] A. da Silva and D. Falcao, "Bibliography on power system state estimation (1968-1989)," IEEE Trans. Power Systems, vol. 5, pp. 950961, 1990.

[18] Aliakbar Mohammadi, "A Novel Approach to Power System Controller Design," International Review on Modelling and Simulations, Vol. 4. N. 5, pp. 2348-2354, 2011.

[19] D. Thukaram, et al., "A robust three-phase state estimation algorithm for distribution networks," Electric Power Systems Research, vol. 55, pp. 191-200, 2000

[20] Y. Deng, et al., "A branch-estimation-based state estimation method for radial distribution systems," IEEE Transactions on Power Delivery, vol. 17, pp. 1057-1062, 2002.

[21] M. Karimi, H. Mohamad, H Mokhlis, A. H. A. Bakar, " UnderFrequency Load Shedding Scheme for Islanded Distribution Network Connected with Mini Hydro," International Journal of Electrical Power \& Energy Systems, vol. 42, pp. 127-138, 2012.

[22] U. Rudez and R. Mihalic, "Monitoring the First Frequency Derivative to Improve Adaptive Underfrequency Load-Shedding Schemes," IEEE Transactions on Power Systems, pp. 1-1, 2011.

[23] M. Karimi, et al., "Impact of load modeling in distribution state estimation," in IEEE International Power Engineering and Optimization Conference (PEOCO) Malacca, Malaysia, pp. 67-71, 2012. 